TITLE:

\title{
CONTRIBUTIONS TO JAPANESE ASCIDIAN FAUNA, XVIII ASCIDIANS FROM SADO ISLAND AND SOME RECORDS FROM SAGAMI BAY
}

\author{
$\operatorname{AUTHOR}(\mathrm{S}):$ \\ Tokioka, Takasi
}

\section{CITATION:}

Tokioka, Takasi. CONTRIBUTIONS TO JAPANESE ASCIDIAN FAUNA, XVIII ASCIDIANS FROM SADO ISLAND AND SOME RECORDS FROM SAGAMI BAY. PUBLICATIONS OF THE SETO MARINE BIOLOGICAL LABORATORY 1962, 10(1): 1-20

ISSUE DATE:

1962-07-30

URL:

http://hdl.handle.net/2433/175302

RIGHT: 


\title{
CONTRIBUTIONS TO JAPANESE ASCIDIAN FAUNA, XVIII \\ ASCIDIANS FROM SADO ISLAND AND SOME RECORDS FROM SAGAMI BAY ${ }^{1)}$
}

TAKASI TOKIOKA

\author{
Seto Marine Biological Laboratory
}

Plates I-III and 4 Text-figures

The present part of the serial studies includes the results of examinations on the following three materials :

i-Collection made at Sikine Island far south off Simoda Port near the distal end of Izu Peninsula. This contains three species-

6. Polycitor proliferus (ОКА)

9. Ascidia aperta (SluIter)

16. Polycarpa cryptocarpa var. kroboja (OKA)--

and was submitted to my examination by Miss Shigeko OHIsHI of the Faculty of Fisheries of Mié University who had collected them.

ii-Two colonies of compound ascidians collected near Enosima in Sagami Bay by Dr. Y. Hirosaki of the Enosima Aquarium. They are

3. Leptoclinides rugosum $\mathrm{n}$. sp. and

13. Botrylloides violaceus Ока.

iii-Collection made at Sado Island in the Japan Sea. This comprises nineteen species and was offered me for examination by Mr. Hisaaki IwasAwa of the Sado Marine Biological Station of Niigata University.

1. Amaroucium pliciferum REDIKORZEV

2. Trididemnum savignii (HERDMAN)

3. Leptoclinides rugosum n. sp.

4. Leptoclinum mitsukurii (ОкА)

5. Eudistoma sp. aff. rubra TOKIOKA

7. Perophora formosana (OKA)

8. Ciona intestinalis (LINNAEUS)

1) Contributions from the Seto Marine Biological Laboratory, No. 379.

Publ. Seto Mar. Biol. Lab., X (1), 1962. (Article 1) 
10. Ascidia sydneiensis samea (OKA)

11. Ascidia ahodori OKA

12. Botryllus tuberatus RitTER \& FORSYTH

13. Botrylloides violaceus OKA

14. Symplegma japonica $\mathrm{n} . \mathrm{sp}$.

15. Polyzoa pacifica ТокIокA

16. Polycarpa cryptocarpa var. kroboja (ОKA)

17. Cnemidocarpa areolata (HELLER)

18. Styela partita (STIMPson)

19. Styela clava var. symmetrica TokiokA

20. Halocynthia hilgendorfi $\mathrm{f}$. ritteri (OKA)

21. Halocynthia roretzi (v. DRASCHE)

In all, twenty-one species are dealt with in this paper and two of them seem to be new to science. Records of Amaroucium pliciferum, Perophora formosana and Polycarpa cryptocarpa var. kroboja at Sado and that of Ascidia aperta at Sikine are to be noted as the northern-most ones for these warm-water forms. Before going to the descriptions, I want to express my hearty thanks to the above-mentioned scientists who gave me so kindly the chance to examine these specimens.

\section{Amaroucium pliciferum REDIKORZEV}

(P1 II. fig. 12)

Two small colonies in the material from Sado. One is $27 \mathrm{~mm} \times 13 \mathrm{~mm}$ in extent and $10 \mathrm{~mm}$ in thickness, while the other is $20 \mathrm{~mm} \times 11.5 \mathrm{~mm}$ in extent, with a $8 \mathrm{~mm}$ thickness and carrying an additional minute mass along its side. The test is whitish, translucent and rather hard gelatinous on the surface, but soft in the inside. The surface is generally smooth and quite free from foreign materials in the latter colony, while it is irregularly depressed and elevated in the former one as shown in Pl. II fig. 12 and provided with one to two common cloacal apertures in each depression. Strongly contracted zooids are only $1.5 \mathrm{~mm}$ in length, postabdomen long or short. Ovary and testis are situated just posterior to the intestinal loop in short postabdomens, whereas in long postabdomens the ovary is found at the middle of a conspicuous space between the posterior end of the intestinal loop and the proximal end of the testis. Atrial languet trifid at the tip. Stigmatal rows 13-14, anus situated at the level of the 9th transverse vessel. Stomach with 23-29 longitudinal plications in examined zooids. A pair of coeca at the proximal end of the rectum. Larvae about $680 \mu$ in trunk length; three attachment processes arranged lineally and the pigment flecks of the sensory organ are arranged antero-posteriorly. 


\section{Trididemnum savignii (HERDMAN)}

(Pl. II, figs. 13-16 ; Text-figs. 1-2)

There are two samples from Sado. One consists of three small colonies, respectively $6 \mathrm{~mm} \times 19 \mathrm{~mm}, 4 \mathrm{~mm} \times 10 \mathrm{~mm}$ and $4 \mathrm{~mm} \times 6 \mathrm{~mm}$ in extent and $1-2 \mathrm{~mm}$ in thickness, while the other includes two larger colonies, respectively $20 \mathrm{~mm}$ $\times 25 \mathrm{~mm}$ and $60 \mathrm{~mm} \times 4-15 \mathrm{~mm}$ in extent and up to $2 \mathrm{~mm}$ in thickness. Test is soft gelatinous. On the smaller colonies, the thoracic layer is transparent and dark brownish thorases are seen through completely, while the periphery of the colony and the abdominal layer are faintly milky white and rather opaque. Spicules are generally distributed on the bottom of the thoracic layer and in the abdominal layer, but they are scarcely found in the thoracic layer itself in the largest colony or found there in small numbers in smaller ones. Spicules are 20 to $43 \mu$ in diameter; rays rather stout, bluntly pointed at the tip, and up to nine on the equatorial plane. One or two roundish common cloacal apertures on each colony; they are usually 400 to $500 \mu$ in diameter, though they may be somewhat larger or opened at the tip of a short siphonal projection. Hypothoracic lacunae well developed.

On larger colonies, both the thoracic and abdominal layers are nearly transparent. The lacuna system is very distinct and spacious between these layers and the lacuna wall is sprinkled with spicules, which are much larger than in the former colonies, attaining 50-90 $\mu$ in diameter and provided with 12-15 rather short, bluntly pointed rays on the equatorial plane. Thorases are reddish brown in colour and moreover brownish pigments are deposited on the bottom of the thoracic layer. The upper side of the colonies, therefore, looks brownish as a whole, while on the underside the whitish lacuna system can be seen distinctly against the brownish background.

All thorases are contracted strongly, 310-350 $\mu$ in length and up to $540 \mu$ in breadth; abdomen $450-550 \mu$ in length. Distances between zooids are $370-570 \mu$ in smaller colonies. The pigmentation of the thoracic mantle is heavier on the anterior side. Retractile muscle is generally shorter than contracted thorax. The apex of the testis is slightly protruded. Testicular follicle one, the proximal end of the vas deferens coils mostly clockwise and up to eight times. The ovary is located on the lateral side of the testis, the two organs being bounded by the proximal portion of the straightened part of the vas deferens between them.

Larvae are $620-840 \mu$ in trunk length. Three cup-shaped attachment processes are arranged lineally. Four pairs of bulbs are present. Pigment flecks of the sensory organ are arranged dorso-ventrally. Larval test granulated.

There were found two larvae quite freely in the bottle in which the larger colonies were kept together with colonies of Symplegma. One (Text-fig. 1) is 
ovoid in shape and $1450 \mu$ in length, while the other is somewhat elliptical and $1100 \mu$ in length. The former is provided with a shrunk tail, three disc-shaped attachment processes arranged in a triangle and nine bulbs surrounding the bases of the stalks of the attachment processes, but quite devoid of sensory organ.

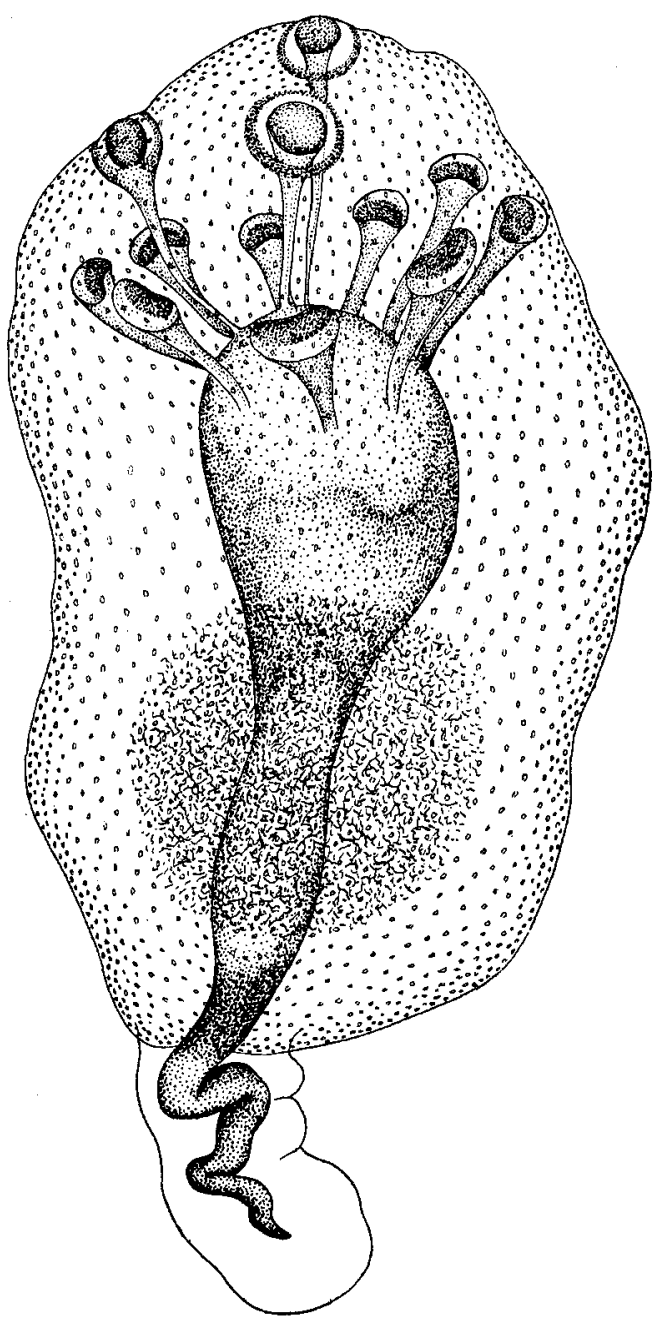

Text-fig. 1. Overgrown larva of ? Trididemnum savignii (HERDMAN) from Sado Island, $\times 73$.

The tip of each bulb is somewhat lunate. While, the other (Text-fig. 2) is devoid of tail, but provided with three disc-shaped attachment processes arranged lineally, eight bulbs in different degrees of development and a distinct sensory 
organ. There is a remarkable fold on the body surface along the right side of the attachment processes. Larval test is highly granulated in both larvae. Evidently these are advanced stages of a certain type of larva with attachment processes arranged lineally and four pairs of bulbs. The larva shown in Textfig. 2 seems to represent one of the earlier stages after attachment, while the other is considered rather to be a mal-formed overgrown larva. It is uncertain to what species these larvae belong, although it is not impossible that they belong to Trididemnum savignii (HERDMAN).

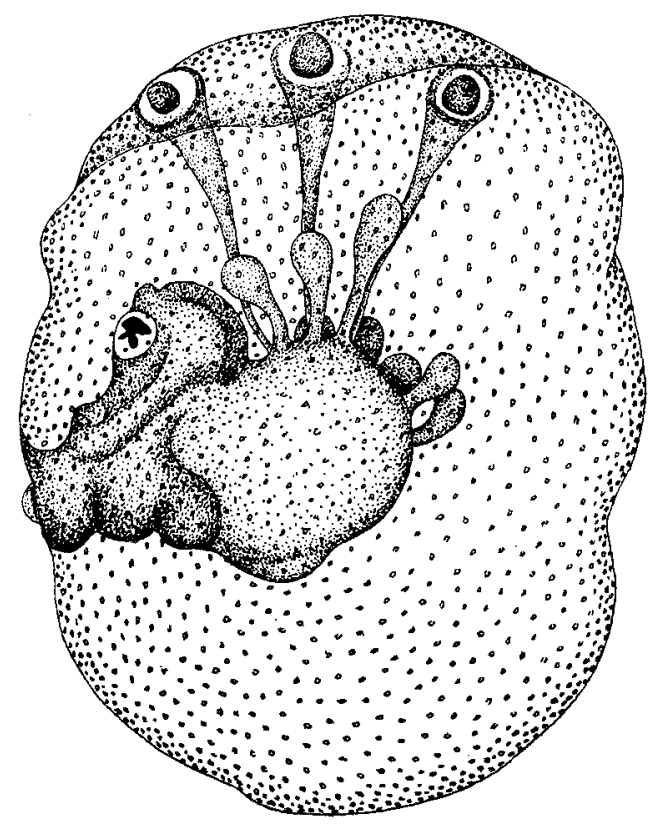

Text-fig. 2. Larva of an advanced stage of ? Trididemnum savignii (HERDMAN) from Sado Island, $\times 73$.

\section{Leptoclinides rugosum $\mathrm{n}$. sp.}

(Pl. II, figs. 17-18; Text-fig. 3)

Holotype: An elongate ovoid colony, $65 \mathrm{~mm}$ in length and $13-22 \mathrm{~mm}$ in diameter and surrounding the stem of Sargassum sp.; it was collected by Dr. HirosAKI near Enosima on July 1,1956 and preserved in alcohol, hence the colour is faded to yellowish gray.

Paratype: A colony, $50 \mathrm{~mm} \times 15 \mathrm{~mm}$ in extent and ca. $5 \mathrm{~mm}$ in thickness, covering the basal portion of a large specimen of Halocynthia roretzi ( $\mathrm{v}$. DRASCHE) collected by Mr. IWASAWA at Sado. It is preserved in formalin and reddish orange pigments deposited in the surface to subsurface layers remain still unfaded. 
The test is rather hard, cartilaginous on the surface, and gives a kind of stiff feeling to the touch like some kinds of sponges. But, it is gelatinous in the inside. The surface of the colony is covered wholly with many prominences of about $1 \mathrm{~mm}$ long and of various shapes and looks like that of Pyrosoma atlanticum PÉron. Common cloacal apertures oval, and up to $1.5 \mathrm{~mm}$ in diameter.

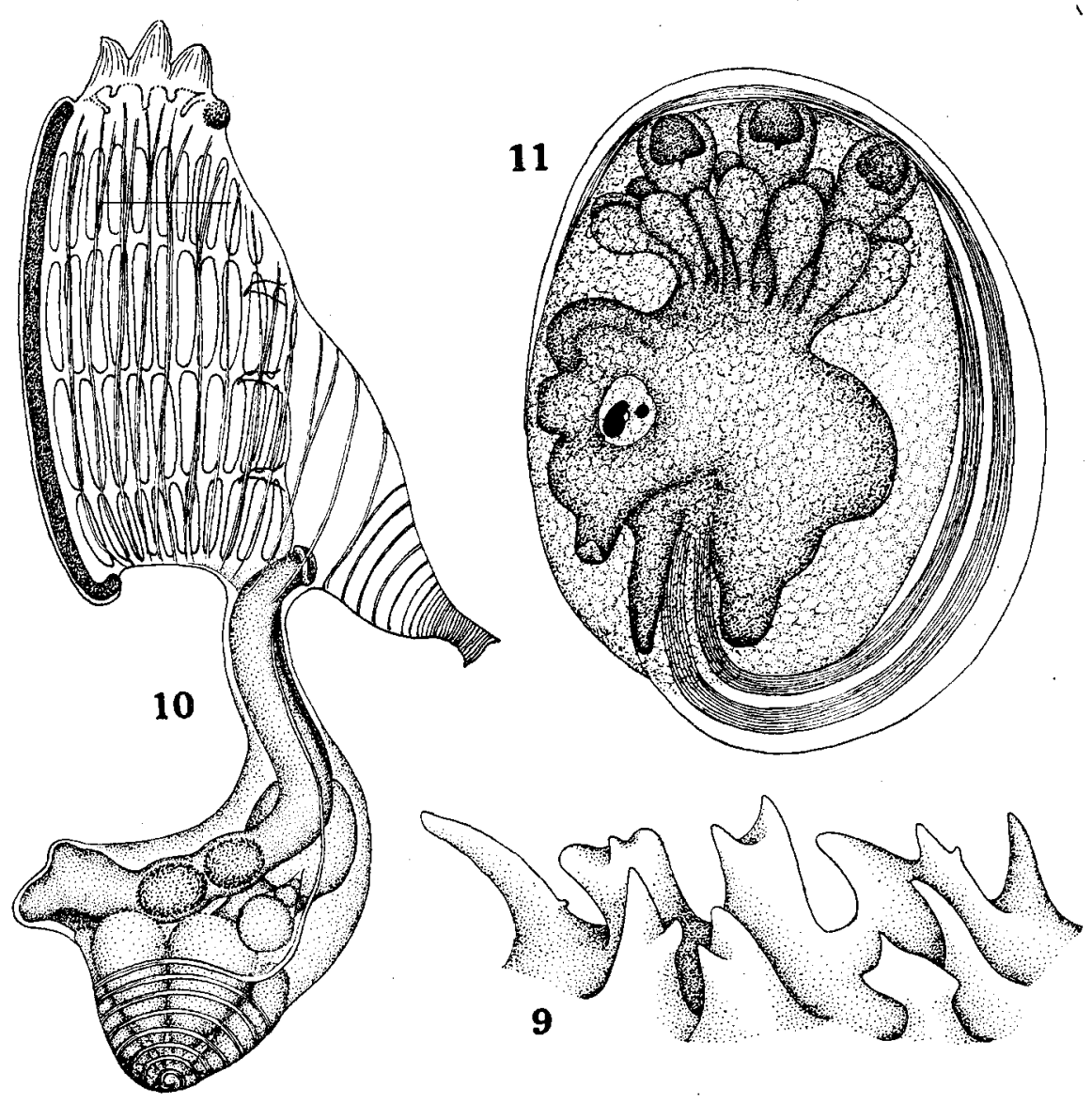

Text-fig. 3. Leptoclinides rugosum n. sp.

9 -Protuberances found on the colony surface, enlarged; 10-Zooid from the left side, enlarged ; 11 - Right side of embryo, $\times 73$.

Spicules quite absent. Many fertilized ova and embryos are found embedded in the bottom layer. The thickness of the colony may attain $6 \mathrm{~mm}$.

Zooids are large, thorax is $1000-1200 \mu$ in length and with the branchial siphon often attaining up to $410 \mu$, neck of a moderate length, and abdomen is $930-1400 \mu$ in length. Branchial spertures 6-lobed, ten to twelve longitudinal muscles on 
each side of the thorax, and atrial siphon is very prominent and extended dorsoposteriorly. Eight to eleven stigmata in each of four rows. Tentacles 8, four larger and the same number of smaller ones alternate regularly. Ciliated groove is an orifice. Hind-stomach is slightly shorter than stomach, mid-intestine is larger than one half of hind-stomach and may be up to nearly the whole length of the latter. The proximal end of the rectum is swollen and constricted very distinctly from the mid-intestine near the posterior end of the abdomen. Testicular follicles 4-10, the proximal end of the vas deferens coils 6-10 times, most frequently it is winded anticlockwise. Ovary is situated along the anterior side of testis (cf. that of Trididemnum savignii, Pl. II, fig. 14).

Larvae were found only in the holotype. They are $860-950 \mu$ in trunk length. Trunk is ellipsoidal, with three cup-shaped attachment processes arranged lineally and $12-16$ bulbs. Probably the existence of six pairs of bulbs is the fundamental feature for larvae of the present species. Pigment flecks of the sensory organ are arranged dorso-ventrally or obliquely. The atrial siphon is distinctly discernible on the larval zooid. Larval test is somewhat frothy.

Remarks: The present new species resembles most closely Leptoclinides echinatum TokıokA 1954 from Osaka Bay in the echinate appearance of the colony surface, although the latter contains spicules in the test. At present, it is not certain whether the existence or absence of spicules is to be appreciated as a specific criterion or not and, therefore, the present specimens which are devoid of spicules completely are treated here provisionally as a different species distinct from $L$. echinatum.

\section{Leptoclinum mitsukurii (OKA)}

Two colonies from Sado, respectively $13 \mathrm{~mm} \times 25 \mathrm{~mm}$ and $6 \mathrm{~mm} \times 14 \mathrm{~mm}$ in extent and $3 \mathrm{~mm}$ in thickness; this is, however, the thickness of double layers. Test is soft gelatinous, milky white in different degrees and thus it varies from transparent to translucent. The larger colony is sprinkled over the surface with many whitish spots which are 55-64 in diameter and each packed with minute granules, the smaller colony is, however, devoid of such spots. The lacuna system is very spacious. Abdomens are placed horizontally. Thoracic and abdominal mantles are pigmented in various degrees in purplish brown to purplish black; the abdominal pigmentation is most remarkable over the testis. Testicular follicles two, ovary situated near the proximal end of the vas deferens. Generally, buds are well developed.

\section{Eudistoma sp. aff. rubrum TokIoxA}

A mutilated colony consisting of a corona of $1.5 \mathrm{~mm}$ high and with a $4 \mathrm{~mm}$ diameter and a basal mass of $4.5 \mathrm{~mm} \times 7 \mathrm{~mm}$ in extent and $5 \mathrm{~mm}$ in height. The 
test is soft gelatinous and quite transparent on the corona, but rather hard, whitish and opaque on the basal mass. Faecal pellets are found deposited on the bottom of the corona. Thorases are all strongly contracted, about $500 \mu$ in length; 7-8 longitudinal muscles on each side, but no transverse ones. About six stigmata in each of three rows. Abdomens are quite mutilated. As there are 12-20 stigmata in each row in zooids of the typical colonies from the Tokara Islands, zooids of the present colony seem to have too fewer stigmata in each row ; and, therefore, I hesitate to identify this colony decidedly with E. rubrum.

\section{Polycitor proliferus (OKA) \\ (Pl. I, fig. 1)}

Nine colonies from Sikine Island, larger ones attain $7 \mathrm{~mm} \times 13 \mathrm{~mm}$ or $8 \mathrm{~mm} \times$ $12 \mathrm{~mm}$ in extent and $2-5 \mathrm{~mm}$ in thickness. Six stigmatal rows are present. From eighteen to twenty-four longitudinal plications on the stamach surface, some may be quite irregular. The trunk of larva is ellipsoidal in shape, about $880 \mu$ in length. Three disc-shaped attachment processes are arranged lineally. Twenty (ten pairs of) vascular follicles are found, including a pair situated near the middle of the ventral side far apart from the anterior end. Pigment flecks of the sensory organ are arranged obliquely. Larval test is granulated.

\section{Perophora formosana (OKA)}

(Pl. II, fig. 19)

Four zooids from Sado, all less than $2 \mathrm{~mm}$ in length. The test is thin and quite transparent. The mantle is quite transparent, too. In two zooids, how. ever, pigmentation made of yellowish corpuscles is found at places on the branchial sac. The mantle musculature consists of transverse muscles, their dorsal ends encircle the atrial aperture just as in the orientalis-form. About 20 stigmata in each of five rows, some of the first and the second rows are continuous with each other. The stomach is rather short, the mid-intestine very distinct. The circum-intestinal gland consists of many vessels covering the intestinal wall and a common vessel leading to the inner pyloric corner of the stomacn (Pl. II, fig. 19). The testicular follicle one, the vas deferens is issued from the dorsal end or the posterior side of the testis. The ovary is found on the way of the vas deferens.

\section{Ciona intestinalis (LINNAEUS)}

A strongly contracted $13 \mathrm{~mm}$ long mantle body enclosed in the mutilated soft gelatinous test. As yellowish corpuscles are sprinkled over some parts of 
the body, the animal might possibly be coloured reddish orange while it was alive. Collected at Sado.

\section{Ascidia aperta SLUITER}

(Pl. I, figs. 2-7)

Thirty specimens from Sikine Island. They are 9 to $34 \mathrm{~mm}$ in length. The body is roughly oval, attached to the substratum by the whole left side. Branchial aperture terminal and 8-lobed, atrial aperture is situated near the middle of the body and 8-9 lobed; margin of each lobe not pectinated. The test is gelatinous, rather hard, and transparent or slightly yellowish. The surface is nearly smooth, but may be sprinkled sparsely with small obtuse papillae. The exposed surface of the test is wholly or partly covered with a thin layer of black volcanic ashes. The right side of the mantle is entirely reticulated with muscles. This side of the body, the siphons and tentacles are sometimes coloured reddish. Generally the anterior end of the intestinal loop does not reach beyond the anterior basal margin of the atrial siphon, although it may reach more

\begin{tabular}{c|c|c|c}
\hline \hline Body length & Tentacles & $\begin{array}{c}\text { Inner longitudinal } \\
\text { vessels } \\
\text { one side }\end{array}$ & $\begin{array}{c}\text { Transverse } \\
\text { vessels }\end{array}$ \\
\hline $18 \mathrm{~mm}$ & 41 (large \& small) & 27 & 57 \\
$18 \mathrm{~mm}$ & 30 & 32 & 58 \\
$20 \mathrm{~mm}$ & ca. 30 & 57 & ca. 30 \\
$34 \mathrm{~mm}$ & excluding minute ones & 42 & ca. 100 \\
\hline
\end{tabular}

anteriorly in some unusually contracted specimens. Usually large and small tentacles alternate regularly, besides a minute one intervenes at some intervals. Inner longitudinal vessels are generally 30-40. Transverse vessels are arranged in the order of 13231 , where numerals show the order of thickness. Parastigmatic vessels are found at places, intermediate papillae present at the level of each parastigmatic vessel and also in some larger specimens even at some intervals in the anterior part of the branchial sac quite free from the parastigmatic vessels. Plications indistinct, three to five stigmata in each mesh. Ciliated groove is crescent or U-shaped and apart from the dorsal ganglion for a half of the ganglion's length. Dorsal lamina is ribbed, the tip of each rib protrudes out from the margin of the lamina.

Stomach roundish, the second intestinal loop is very shallow and its axis passes through the oesophageal region. The vessel connecting the pyloric end of the stomach with the intestine is very distinct. The ovary is an elongate gland running along the intestine at the bottom of the first intestinal loop and provided with up to ten branches; the ovidust is issued from the posterior end 
of the organ and proceeds along the inner margin of the proximal half of the loop. Testicular follicles are spread over the right side of the stomach and the following proximal portion of the intestine. Ovary matured on a $18 \mathrm{~mm}$ long specimen and testis matured on a $20 \mathrm{~mm}$ long specimen; proterogynic.

There are many small round vacuoles containing each an orange brown body inside distributed in the area extending from the stamach to the ovary just as in the specimens from the Tokara Island. Evidently, the present locality is the northern-most one for this species. And it seems to be noteworthy that many smaller specimens are found matured at this northern locality.

\section{Ascidia sydneiensis samea (OKA)}

$$
\text { (Pl. III, fig. 20) }
$$

Five specimens from Sado ; they are 24 to $47 \mathrm{~mm}$ in length. The branchial siphon is terminal and fairly long attaining $15-16 \mathrm{~mm}$ in some specimens, the atrial siphon is situated at the middle or a little anteriorly. The branchial aperture is $7-8$ lobed and the atrial is $5-6$ lobed, margin of each lobe pectinated.

\begin{tabular}{c|c|c|c}
\hline Body length & Tentacles & $\begin{array}{c}\text { Inner longitudinal } \\
\text { vessels } \\
\text { on one side }\end{array}$ & $\begin{array}{c}\text { Transverse } \\
\text { vessels }\end{array}$ \\
\hline $41 \mathrm{~mm}$ & ca. 70 & (left) $50-51$ (right) & ca. 100 \\
$45 \mathrm{~mm}$ & $50-60$ & 35 & ca. 90 \\
$47 \mathrm{~mm}$ & 36 (large ones only) & $39-43$ & 75 \\
$47 \mathrm{~mm}$ & $42-41$ & 78 \\
\hline
\end{tabular}

The test is cartilaginous, thin but rather hard. It is transparent or translucent and colourless, whitish or pale brownish in colour. The surface is nearly smooth in some specimens, but it is usually irregularly wrinkled or furnished with irregularly formed swellings or protuberances and rarely carries some foreign materials. Frequently a number of branched vascular vessels are issued from the surface of the mantle body. Usually the anterior end of the intestinal loop does not reach beyond the anterior margin of the base of the atrial siphon, althouth it may reach a little anteriorly in some specimens. Large and small tentacles alternate regularly, besides a minutes one at some intervals. The ciliated groove is simple and U-shaped in the $24 \mathrm{~mm}$ long specimen, but it is complicated in other larger ones. The dorsal tubercle is situated at the anterior end of the dorsal ganglion, sometimes apart from the ganglion for a half of the tubercle's length. Branchial plications are distinct, about six stigmata in each mesh, intermediate papillae absent. The dorsal lamina is ribbed, the tip of ribbs does not project out from the laminal margin.

The stomach is rather elongate, no distinct plications can be seen on the surface. The axis of the second intestinal loop passes through the pyloric end 
of the stomach or a little behind it. The intestine is somewhat swollen at the bottom of the second loop.

\section{Ascidia ahodori OKA}

(Pl. III, fig. 21)

Two specimens from Sado. The larger one is $41 \mathrm{~mm}$ long, $20 \mathrm{~mm}$ wide and $13 \mathrm{~mm}$ thick, while the smaller one is only $13 \mathrm{~mm}$ long and yet fully matured. On the larger specimen, the branchial siphon is terminal and the atrial aperture is opened at the level of the anterior one third of the body and marked with six orange ocelli. The test is thick, hard gelatinous, milky white and translucent; the surface is nearly smooth and marked faintly with wrinkles. It is very thin on the attachment surface. The right side of the mantle body is wholly reticulated with muscles, of which longitudinal or oblique ones are dominant. The anterior end of the intestinal loop reaches slightly beyond the level of the anterior margin of the base of the atrial siphon. The stomach is large, elliptical ; the axis of the second intestinal loop passes through the stomach near the pyloric end. Tentacles are about 30 exclusive of minute ones, large and small ones are alternating. The ciliated groove is simple and U-shaped, apart from the ganglion approximately for the tubercle's length in a strongly contracted state. Dorsal lamina ribbed, tip of each rib protrudes out from the margin. Inner longitudinal vessels are 34 (left side)-39 (right side), transverse vessels about 145, intermediate papillae absent. About one distinct plication at each interval between longitudinal vessels, up to ten stigmata on each plication.

On the smaller specimen, the test is soft gelatinous, transparent and attached to algal filaments along all sides of the body. The branchial siphon terminal and the atrial is situated slightly behind the middle of the body, with the anterior margin of its base just at the middle. Both siphons short; the branchial aperture is 8 -lobed and the atrial is 6 -lobed. The right side of the mantle body is wholly reticulated with muscles. The anterior end of the intestinal loop reaches beyond the middle of the range between both siphons. The second intestinal loop is shallow but distinct, the axis passes through the middle of the stomach. Tentacles 16 comprising large and small ones, besides some minute ones. The ciliated groove is $\mathrm{C}$-shaped opened anteriorly. Inner longitudinal vessels are 21 (left side)-25 (right side), transverse vessels are 60-70 and arranged in the order of - thick thin medium thin thick-, intermediate papillae absent. Plications not remarkable, about three stigmata in a mesh. Most probably, this is a dwarf individual of $A$. ahodori attained the maturity at such a small size. 


\section{Botryllus tuberatus RITTER \& FORSYTH}

A $75 \mathrm{~mm}$ long colony from Sado, encrusting the stem of Sargassum; some parts are formed into lobes of about $3 \mathrm{~mm}$ thickness. The test is milky white to pale brownish and translucent. Zooids are pigmented in purplish brown.

\section{Botrylloides violaceus OKA}

(P1. III, fig. 22)

Six colonies from Sado and a single colony from Enosima. As the variations found in the forms identified as $B$. violaceus are remarkable, it is desirable to gather data about such variations so that their nature or significance can be recognized properly. For this reason, the above-mentioned colonies are described respectively.

i) A $75 \mathrm{~mm} \times 15 \mathrm{~mm}$ colony from Sado, encrusting Sargassum in double layers attaining $7 \mathrm{~mm}$ in thickness and pale brownish in formalin; it is not certain whether this pale colouration is natural one or caused by fading. Zooids up to $2.25 \mathrm{~mm}$ in length, located vertically. Tentacles 8 ; stigmatal rows 15 to 16 on the left and 14 to 15 on the right side; about 15 stigmata in a row on each side, 3-4 stigmata in wider spaces and 3 in narrow ones. The second row does not reach the dorso-median line. The anus is situated at the level of the 11th transverse vessel. Ten to eleven longitudinal plications on the stomach surface. The testis on the left side is situated with its anterior margin at the 11th transverse vessel, while on the right side it is covering the stomach; testicular follicles 10-14. The ovary contains usually only a single mature egg and projects out from the dorso-posterior corner of the left testis or from the dorsal side of the right testis.

ii) Three pnrplish brown colonies from Sado encrusting the stem of Sargassum. They are respectively $40 \mathrm{~mm} \times 15 \mathrm{~mm}, 7 \mathrm{~mm} \times 31 \mathrm{~mm}$ and $10 \mathrm{~mm} \times 35 \mathrm{~mm}$ in extent. The first colony contains no zooids with mature gonad, while the last one includes zooids sexually matured. On the second colony, zooids are all contracted to a small size, ca. $660 \mu$ in length, and completely buried within the test, and instead a number of tadpole larvae are found in the test. Fully extended zooids are up to $4 \mathrm{~mm}$, stigmatal rows are $12-14$ on the left and 12-13 on the right side. The anus is situated at the level of the 10th transverse vessel. From 10 to 12 longitudinal plications on the stomach surface. Testis is located along the anterior margin of the intestinal loop on the left side, but covering the stomach on the right side; testicular follicles are 6-13. Larvae very large; the trunk is roughly spherical, up to $1.5 \mathrm{~mm}$ in long diameter. Three small attachment processes are arranged in a triangle. Up to 30 elongate bulbs and 8 zooidal ampullae are found in examined specimens. The posteroventral side of the trunk is

$$
-12-
$$


protruded out posteriorly. Larval test is finely granulated.

iii) Two small reddish brown colonies from Sado; they are respectively $8 \mathrm{~mm} \times 14 \mathrm{~mm}$ and $5 \mathrm{~mm} \times 12 \mathrm{~mm}$ in extent and $2.5-3 \mathrm{~mm}$ in thickness. Zooids are situated a little obliquely. Ten to eleven stigmatal rows on the left and nine to ten on the right side, the dorsal end of the second row does not attain the median line. The anus is situated at the level of the 6 th or the 7 th transverse vessel. Eight to nine longitudinal plications on the stomach surface.

iv) A large purplish brown colony from Enosima collected on July 22, 1956, encrusting a Zostera leaf, $20 \mathrm{~mm} \times 200 \mathrm{~mm}$ in extent and $5 \mathrm{~mm}$ in thickness. Zooids are mostly small, ca. $1 \mathrm{~mm}$ in length, and many larvae in various developmental stages are contained in the test. Stigmatal rows nine on each side and about 12 stigmata in each row; the anus is situated at the level of the 7th transverse vessel. Stomach with ten longitudinal plications on the surface. The testis was found only on one side, left or right, in examined zooids; testicular follicles $5-10$.

\section{Symplegma japonica n. sp.}

(Text-fig. 4)

A single colony from Sado. This consists of a number of masses of different sizes connected one another by stolon, and respective masses include from one to about forty elliptical zooids. Zooids up to $4 \mathrm{~mm}$ in length, lying and surrounded along the periphery by a number of oval or elliptical ampullae which are $300-430 \mu$ in long diameter. When the mass contains only a single zooid, its appearance reminds us somewhat of Symplegma viride stolonica BERRILL. The test is extremely thin, quite transparent and zooids are seen through it completely. The mantle is thin, too; musculature consists of delicate muscles, chiefly consisting of a group of muscles converging on the atrial aperture and another group of muscles traversing between both apertures. There are a number of vessels generally containing yellowish corpuscles, thus the zooids look yellowish as a whole. The branchial aperture is subterminal and the atrial aperture is situated near the centre of the dorsal side; both apertures are each a longitudinal slit on the sagittal plane of the body. The atrial aperture is surrounded by 25-30 fine atrial tentacles and there is a small prominence packed with yellowish corpuscles on each lateral side of the aperture outside the ring of the tentacular velumn (fig. 26). Stigmatal rows 8 or 9 on each side, the dorsal end of the second row reaches the median line. Stigmata are distributed in interspaces between four inner longitudinal vessels, dorsal lamina and endostyle as

D. $3-5 \cdot 3-5 \cdot 4 \cdot 4 \cdot 5 \mathrm{~V}$. on the left and

D. $6-7 \cdot 4 \cdot 4 \cdot 3-4 \cdot 3-4 \mathrm{~V}$. on the right side. Two dorsal vessels on the left side 


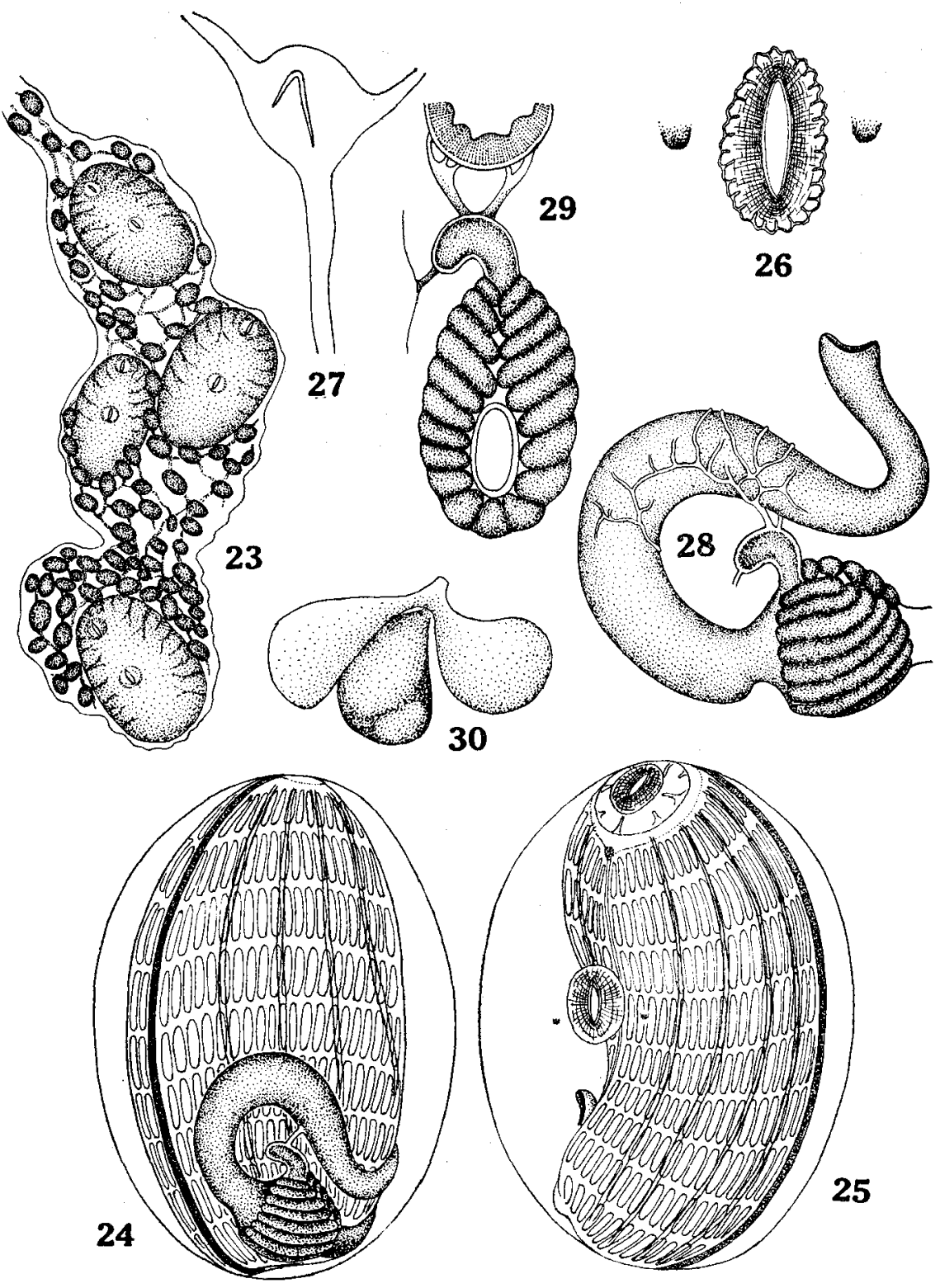

Text-fig. 4. Symplegma japonica $\mathrm{n}$. sp.

$23 \cdots$ A part of the colony, enlarged; $24 \cdots$ Ventral side of zooid, enlarged; $25 \cdots$ Dorsal side of zooid, enlarged; $26 \cdots$ Atrial aperture from inside, magnified; $27 \cdots$ Ciliated groove, magnified; $28 \cdots$ Left side of alimentary canal, enlarged ; $29 \cdots$ Optical sagittal section of alimentary canal near the level of the pyloric coecum, seen from the dorsal side, the cardiac end of stomach is shown below and the section of intestine is given above; $30 \cdots$ Rudimentary gonad, magnified. 
do not reach posteriorly to the rear part of the branchial sac. Parastigmatic vessels absent. Tentacles 8 , large and small ones alternate regularly. The ciliated groove is a longitudinal slit, often hock-shaped. The intestinal loop is less than one half of the body length, with its anterior end at the level of the 5th transverse vessel. The anus is opened on the dorsal side at the 6 th transverse vessel and plainly margined. The stomach is roundish in outline, faintly greenish, and rather small, about half as long as the ventral branch of the intestinal loop. It is provided with 17-20 longitudinal plications. on the surface and a remarkable pyloric coecum that curves conspicuonsly and is connected to the mantle wall by a short vessel issued from the tip and to the intestine by a pair of vessels issued from the middle or the distal one third of the coecum. These vessels are ramified complicatedly on the intestinal wall forming there an orange glandular tissue. Remarkable constriction is formed between the stomach and the intestine.

Gonads are not yet developed in any examined zooids, except for a single zooid in which a pair of rudimentary testicular follicles and a median ovary are observed along the endostyle near the middle on the right side.

Remarks: This colony resembles most closely Symplegma viride HeRdMaN in general appearance of the zooid and in the structure at most parts of the body. However, the exact arrangement of the vessels connecting the pyloric coecum to the mantle and the intestine seems to differ from that of $S$. viride. The longitudinal plications are much shorter on the anterior (not cardiac) half of the stomach and ending to the typhlosole. This seems to differ considerably from the case found in S. viride. Moreover, the second stigmatal row reaches dorsally to the median line in the present new species. All these differences seem to be serious to treat the present specimen simply as S. viride. It is not impossible that the present specimen represents merely a special variant of $S$. viride, but rather I consider, at present, it more reasonable to treat the specimen as a distinct form related most closely to $S$. viride.

\section{Polyzoa pacifica TokiokA, 1951}

(Pl. III, ffg. 31)

TokiokA, T. (1951): Contributions to Japanese Ascidian Fauna IV. Notes on some ascidians collected in Ósaka Bay (1). Publ. Seto Mar. Biol. Lab., I (4), pp. 173-175, text-fig. 4.

Thirty-three nearly spherical or ovoid zooids up to $3 \mathrm{~mm}$ in long diameter. They are attached to the substratum by the left ventral side of the body which is flattened and furnished along the periphery with some extensions of the test. The branchial aperture subterminal and 4-lobed, while the atrial aperture is roundish and situated with its anterior margin just at the middle of the dorsal side, Both apertures are nearly sessile, though they are each opened on a low 
prominence. The test is leathery, considerably thick and very tough; but it is very thin on the attachment surface; it is yellowish white, translucent and the colouration of the dark purplish brown mantle is seen through faintly. The surface is finely wrinkled. A slender vascular vessel is issued from the anteroventral part of the mantle body. There is an elongate vesicle packed with purplish brown corpuscles near the middle on each side. Both the branchial and atrial tentacles could not be examined closely because of strong contraction. About a dozen rows of stigmata and three inner longitudinal vessels on each side. Parastigmatic vessels could not be observed. The ciliated groove is an elongate elliptical opening.

The stomach is provided with a stout pyloric coecum and furnished with fourteen longitudinal plications on the surface, the plications are shortened towards the typhlosole. Gonads are all still rudimentary, up to three on the left and up to 8 on the right side. Although the parastigmatic vessels were not found in the examined zooids, the general appearance and structure of the present specimens conform exactly to those of $P$. pacifica known previously from Ôsaka Bay. The exact comparison between $P$. pacifica and $P$. vesiculiphora TokiokA is still left for a future study.

\section{Polycarpa cryptocarpa var. kroboja (OKA)}

(Pl. I, fig. 8; Pl. III, fig. 32)

A $68 \mathrm{~mm}$ long specimen from Sikine Island and a $55 \mathrm{~mm}$ long specimen from Sado. The following observations are based on the specimen from Sado, this is evidently the northern-most record for this species. The test is leathery and purplish black on the outer layer, but rather gelatinous, soft and dark brownish on the inner layer. It is thick and irregularly corrugate on the surface. The mantle is brownish black in colour. The atrial siphon is situated near the middle of the dorsal side. Fine tentacles on the atrial velumn. Branchial tentacles 13 comprising large and small ones; ciliated groove is simple, V-shaped. Inner longitudinal vessels ard arranged as :-

$$
\begin{array}{lllllllllll}
\text { Left } & \text { D. } 3\left(15^{*}\right) & 3 & (13) & 5(13) & 6(12) & 4 \mathrm{~V} . & & & & \\
\text { Right: } & \text { anterior part } & \text { D. } & 0\left(11^{*}\right) & 6(12) & 5(13) & 7(12) & 6 \mathrm{~V} . & \\
& \text { posterior part } & \text { D. } 2 & \left(5^{*}\right) & 3\left(9^{*}\right) & 5(12) & 5(13) & 7(12) & 6 \mathrm{~V} .
\end{array}
$$

The folds marked with asterisk are represented merely as groups of vessels. The stomach is slender, longitudinal plications are quite obscure on the surface. Three endocarps in the intestinal loop, the inner-most one is very large and the middle one is the smallest. The anal margin is cut in fine lobules. Gonads are distributed evenly and completely buried in the mantle. 


\section{Cnemidocarpa areolata (HELLER)}

Four $9-13 \mathrm{~mm}$ long specimens from Sado. The test is soft leathery, translucent and faintly brownish. The axis of the shallow second intestinal loop passes through the cardiac portion of the stomach. Several endocarps in the first intestinal loop. Three to four gonads on the right and two to three ones on the left side; they are all mature, sometimes branched.

\section{Styela partita (STIMPSON)}

(P1. III, figs. 33-35)

Three 10-15 mm long specimens from Sado. Two of them are roughly ovoid in shape and attached to the substratum by the flattened ventral side where the test is very thin and yellowish brown in colour. On the dorsal side the test is rather thick, leathery and reddish brown in colour. Branchial aperture is subterminal and the atrial is situated near it, both apertures 4 -lobed. Siphons are very short because of strong contraction. The test surface is irrengularly corrugate. The mantle is yellowish white and considerably thick. Another $15 \mathrm{~mm}$ long specimen, shown in figures, is unusually elongate. In this specimen the branchial aperture is terminal and the atrial siphon is enormously lengthened. The inner longitudinal vessels are distributed as:-

$$
\begin{array}{lllllllll}
\text { Left } & \text { D. } & 2(10) & 3(10) & 2(11) & 3(9) & 3 & \text { V. } \\
\text { Right } & \text { D. } & 2(12) & 1(13) & 2(12) & 3(11) & 1 & \text { V. }
\end{array}
$$

Transverse and parastigmatic uessels alternate regularly; six to eight stigmata in each mesh. The stomach is large and elongate, occupying about two thirds of the ventral branch of the first intestinal loop. The axis of the second intestinal loop passes near the cardiac end of the stomach. Two gonads on each side; the ovaries elongate, testicular follicles are spread over the mantle surface surrounding the ovaries. Even the $10 \mathrm{~mm}$ long specimen is already mature.

\section{Styela clava var. symmetrica ТокіокА, 1959}

ToKIOKA. T. (1959): Contributions to Japanese Ascidian Fauna XV. Sporadic memorandum (6). Publ. Seto Mar. Biol. Lab., VII (3), pp. 457-463, 1 text-fig.

A single small specimen from Sado. It is $17 \mathrm{~mm}$ long including a short peduncle, the basal portion of the body marked with longitudinal creases, however, attains $9 \mathrm{~mm}$. The test is leathery and yellowish brown, but the anterior part of the body is furnished with many remarkable knobs and coloured reddish orange between these protuberances. Two fully mature gonads on each side, testicular follicles are arranged just along the periphery of the ovary. 


\section{Halocynthia hilgendorfi f. ritteri (OKA)}

(P1. III, figs. 36-38)

cit. Publ. Seto Mar. Biol. Lab., VII (2), 1959, pp. 233-234, Pl. 17 fig. 43, Pl. 18 figs. 44-47.

A $67 \mathrm{~mm}$ long specimen from Sado. The test is leathery, very hard and up to $5 \mathrm{~mm}$ in thickness. The surface is irregularly corrugate and covered with hydrozoan colonies and small algae. The reddish brown hue of the test surface can be seen after these fouling organisms are cleaned, the inner surface is yellowish white. The branchial aperture is terminal and the atrial aperture is situated with its posterior margin just at the middle of the body. Both apertures are surrounded by a number of yellowish white spines up to $5 \mathrm{~mm}$ in length and furnished with irregularly issued spinules (fig. 36). In addition to these, the whole surface of the body is covered by many spinules up to $0.3 \mathrm{~mm}$ in length (fig. 37). The mantle is yellowish and very thick, $1.5 \mathrm{~mm}-2 \mathrm{~mm}$ in thickness. Large endocarps are found on the inner surface. The inner surface of the distal part of siphons is covered by many minute conical papillae, $7-8 \mu$ in height (fig. 38).

Tentacles are furnished chiefly with branches of the first order, those of the second order are scarcely found. The ciliated groove is rosette-shaped. Nine folds on each side of the branchial sac, the ninth fold is, however, formed only in the anterior part of the sac. The inner longitudinal vessels are arranged on the posterior half of the left side as:
D. $2(38)$
7 (36)
$8(37)$
6 (39)
$7(26) \quad 6$
$6(30)$
$4(23) \quad 3(22)$
$0 \mathrm{~V}$.

Seven yellowish gonads on the right side, one of them is branched into two, those on the left side are obscure because of a serious injury.

\section{Halocynthia roretzi (v. DRASCHE)}

A $40 \mathrm{~mm}$ long specimen from Sado. The body is very bulky, $30 \mathrm{~mm} \times 35 \mathrm{~mm}$ in a section near the middle. The surface is covered with mammillary prominences characteristic to the boreal type of the species. Siphons are very stout, $17-18 \mathrm{~mm}$ in length. The right half of the body is orange, while the left half is whitish. It is not certain whether this asymmetrical colouration is natural one or attributable to fading caused by illumination on the left side only. 
EXPLANATION OF PLATES I-III

\section{Plate I}

Fig. 1. Polycitor proliferus (Ока) from Sikine Island. Right side of larva, $\times 107$.

Figs. 2-7. Ascidia aperta (Sluiter) from Sikine Island.

2-A $18 \mathrm{~mm}$ long specimen.

3-Left side of the mantle body of the same specimen.

4-Right side of the same mantle body.

5,6 -Ciliated grooves of $18 \mathrm{~mm}$ long specimens.

7-Ciliated groove of a $34 \mathrm{~mm}$ long specimen.

Fig. 8. Polycarpa cryptocarpa var. kroboja (ОКA) from Sikine Island. Ciliated groove.

\section{Plate II}

Fig. 12. Amaroucium pliciferum RedIKorzev from Sado Island. A $27 \mathrm{~mm}$ long colony.

Figs. 13-16. Trididemnum savignii (Herdman) from Sado Island.

13-Spicule from a smaller colony, $\times 1200$.

14-Abdomen from a smaller colony, enlarged.

15-Right side of an embryo from a smaller colony, $\times 73$.

16--Spicule from a larger colony, $\times 440$.

Figs. 17, 18. Leptoclinides rugosum n. sp. from Sado Island.

17-Abdomen, enlarged.

18-A part of the colony surface, enlarged.

Fig. 19. Perophora formosana (OKA) from Sado Island. Alimentary canal and gonad, from left side; enlarged.

\section{Plate III}

Fig. 20. Ascidia sydneiensis samea (OKA) from Sado Island. Ciliated groove of a $41 \mathrm{~mm}$ long specimen, magnified.

Fig. 21. Ascidia ahodori Oка from Sado Island. Ciliated groove of a $41 \mathrm{~mm}$ long specimen, magnified.

Fig. 22. Botrylloides violaceus Oka from Sado Island. A larva from the sample (ii), enlarged.

Fig. 31. Polyzoa pacifica TokıoKa from Sado Island. A $3 \mathrm{~mm}$ long zooid, enlarged.

Fig. 32. Polycarpa cryptocarpa var. kroboja (OKA) from Sado Island. Ciliated groove, magnified. 
Figs. 33-35. Styela partita (Stimpson) from Sado Island.

33 - The $15 \mathrm{~mm}$ unusually elongate specimen.

34-Right side of the mantle body of the same specimen, from outside.

35-Left side of the same mantle body, from outside.

Figs. 36-38. Halocynthia hilgendorfi f. ritteri (OKA) from Sado Island.

36 -A $5 \mathrm{~mm}$ long spine from the area surrounding apertures.

37-Spinules on the body surface, enlarged.

- 38-A spinule from the distal inner surface of siphons, $\times 440$. 
Publ. Seto Mar. Biol. Lab., X, 1 (1962)

Plate I
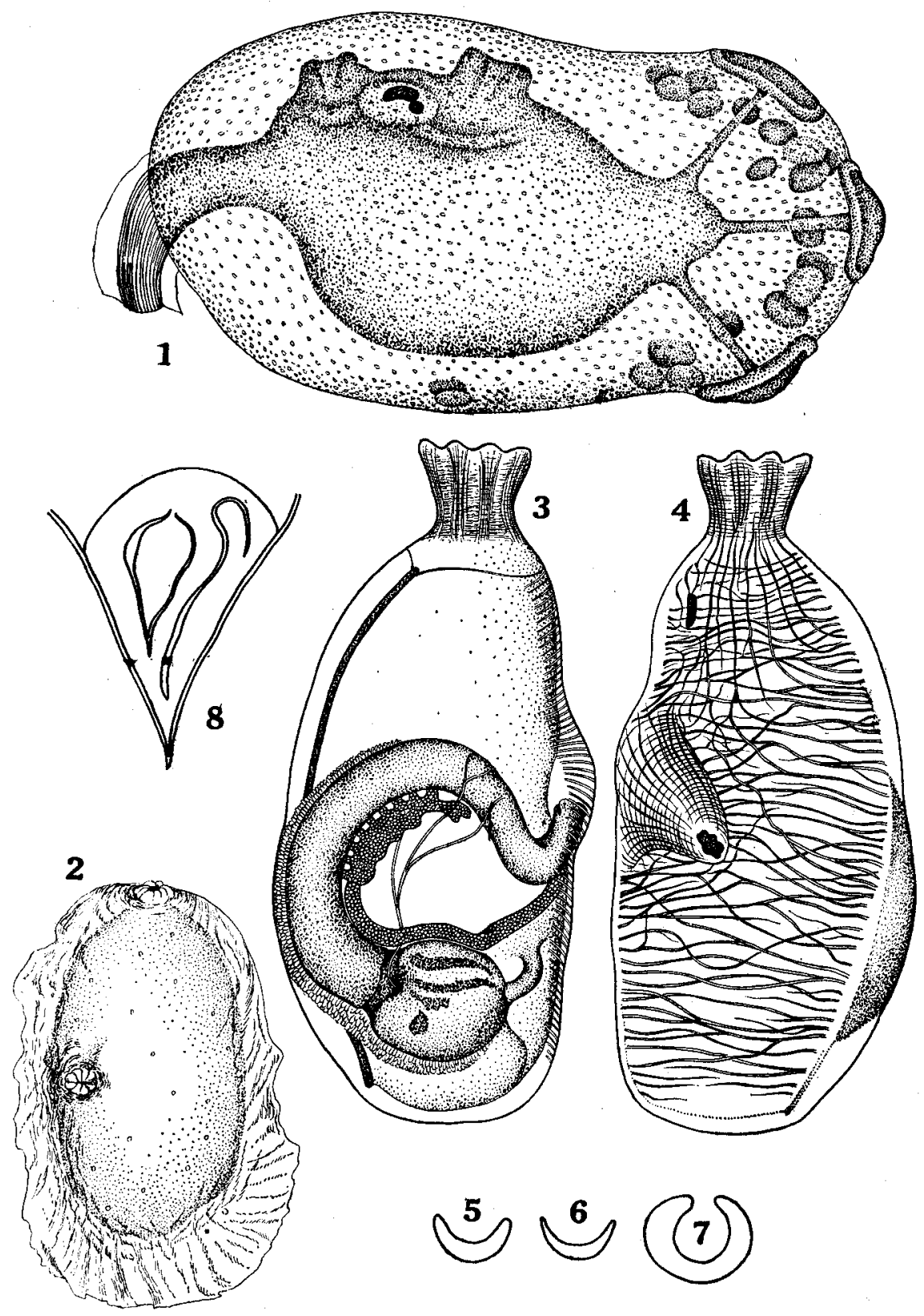

T. Tokioka: Contributions to Japanese Ascidian Fauna, XVIII. 
Publ. Seto Mar. Biol. Lab., X, 1 (1962)
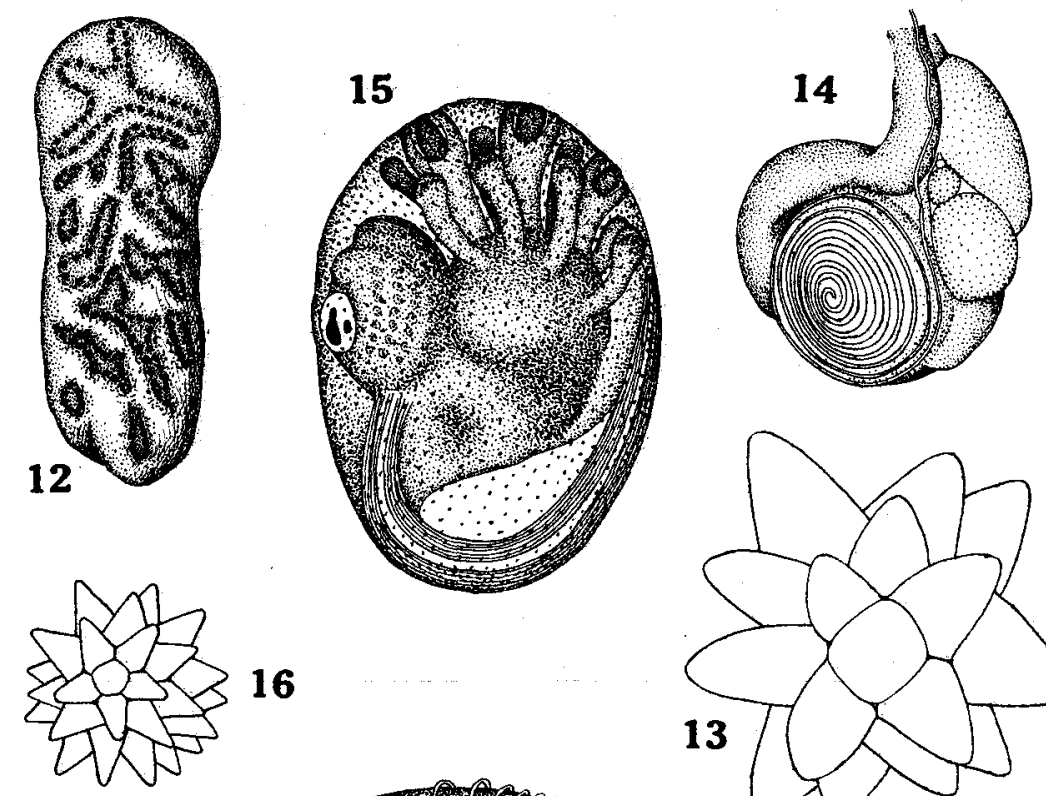

\section{6}
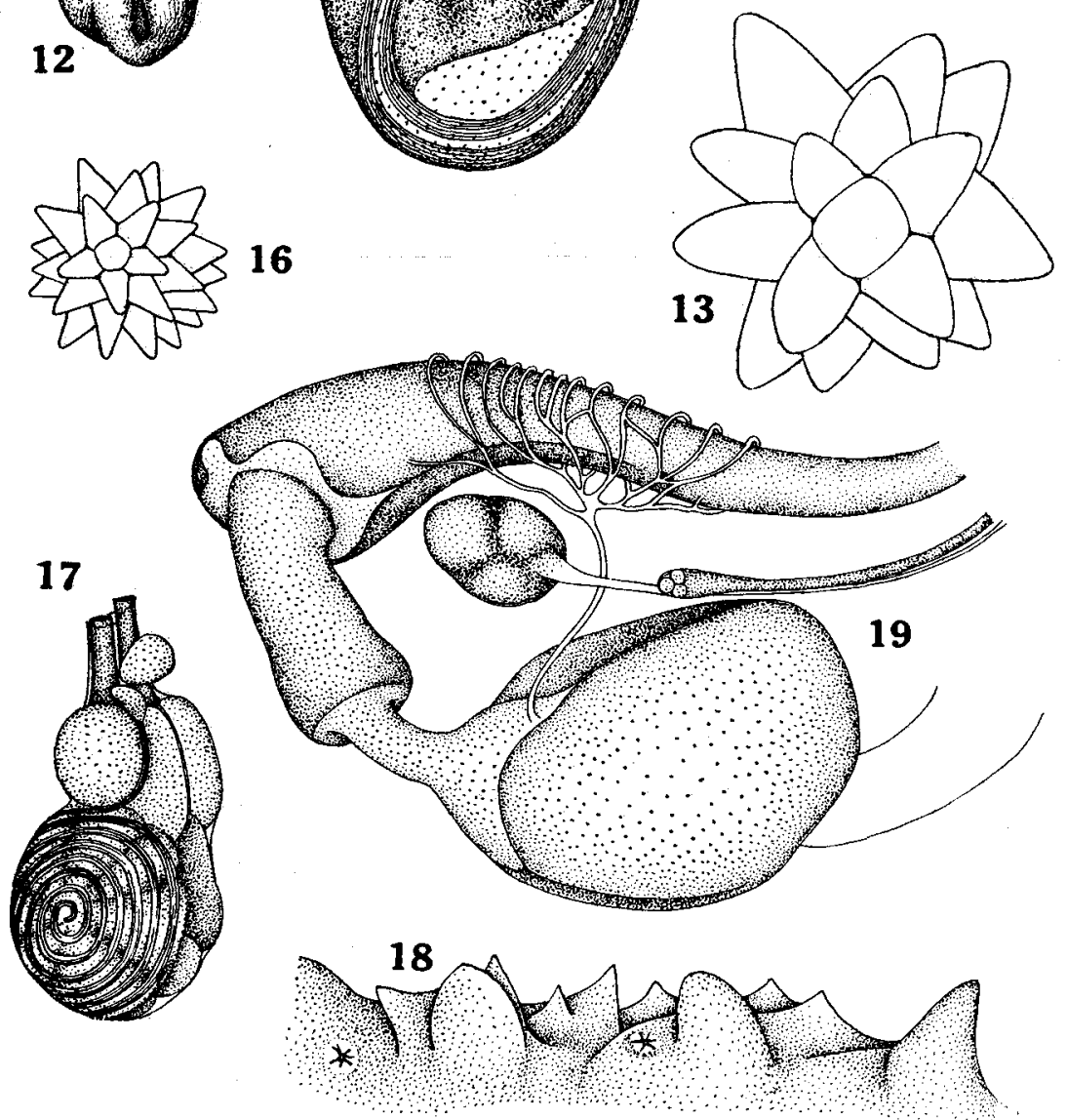

T. Tokioka: Contributions to Japanese Ascidian Fauna, XVIII. 
Publ. Seto Mar. Biol. Lab., X, 1 (1962) PLATE III
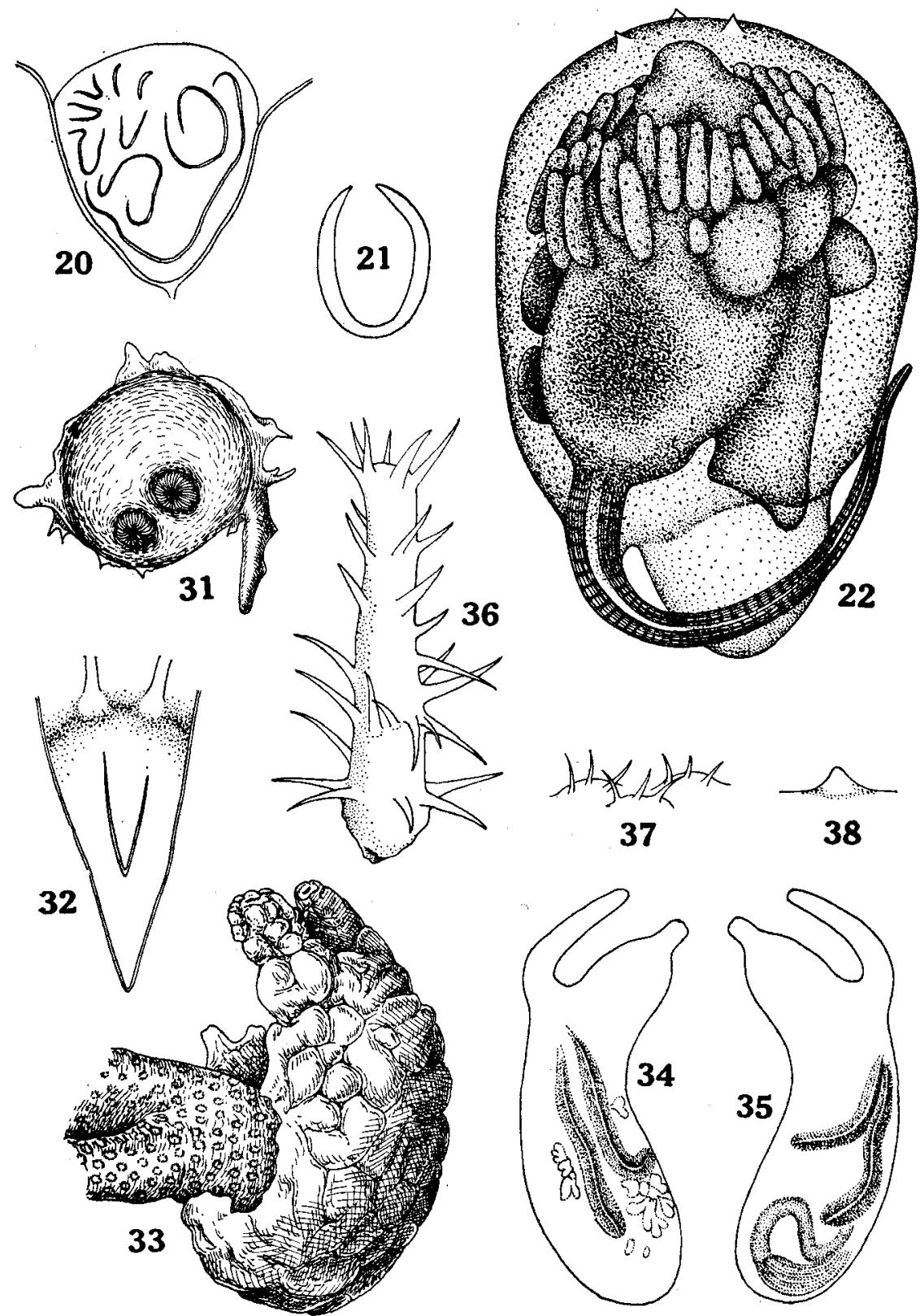

T. Tokioka: Contributions to Japanese Ascidian Fauna, XVIII. 